\title{
Teaching Strategies of Financial Interpretation in the Background of RMB Internationalization*
}

\author{
Ke Yang \\ School of Foreign Languages \\ Southwest Minzu University \\ Chengdu, China 610041
}

\begin{abstract}
With the intensification of globalization and the growing number of financial hot issues on the international scale, China has established a close financial link with the world, bringing about an increasing demand for high-quality and highcalibre interpreters in the financial field. Taking the hot-button issue of the financial internationalization of Renminbi, for example, the problems encountered in interpretation were put forward, such as the differences of technical terms, financial abbreviations or cultural and environmental differences in the financial English, as well as the complex contents of financial problems. The interpreters need to increase their vocabulary, and improve their financial professional and interpretation skills and ability to cope with different environment, which objectively requires them to learn financial professional knowledge, gain a deep understanding of the technical terms and adapt themselves to different scenarios freely. Suggestions on how to launch a reasonable financial strategy in interpretation, improve the level of the interpreters in teaching and interpreting have been proposed, so as to keep up the pace of the financial English, and cater for the market demand for financial interpreters.
\end{abstract}

Keywords-international finance; Financial English; internationalization of Renminbi; teaching strategy of interpretation

\section{INTRODUCTION}

In the context of economic globalization and financial mixed operation, and referring to international practice, there are three main meanings of the word finance: in the narrow sense, it refers to activities related to the operation of capital markets; in a general sense, it includes the circulation of money, the granting of credit, the operation of investment, and banking services. In a broad sense, it can be meticulously divided into public finance, corporate finance, and household finance, and its scope includes the first two. International finance is accompanied by the development of international trade and belongs to the category of macro finance. Before the 19th century, international finance mainly focused on international settlement, currency exchange, discounted bills and other services closely related to the practical economy, and its earliest market form was the foreign exchange market. Since the 1970s, with the rapid development of the world

*Project Information: This thesis is a phased achievement of the general project of Sichuan Ethnic Education Development Research Center, a key research base of philosophy and social sciences in Sichuan Province. Project Name: Research on Interpretation Vocational Education in Sichuan Ethnic Areas. Project No: SEED201810. economy, the implementation of financial liberalization in various countries and the development of electronic communication technologies, the international financial market has undergone tremendous changes. Global integration and financial innovation products have shown an endless trend in the 1980s. Thanks to the relaxation of financial regulation, financial innovation and the development of modern technology, financial markets and financial institutions all over the world have gradually formed a fulltime, all-round integrated international financial market [1].

Since the reform and opening up 30 years ago, China's economy has developed rapidly. Especially in recent years, China's total export trade has increased year by year. In 2014, the total export volume reached 2.34 trillion US dollars, accounting for $13.18 \%$ of the world's total export trade, ranking second in the world. As China becomes the world's largest exporter and the second largest economic system, the RMB is increasingly used in international trade settlement and financial transactions.

\section{PROBLEMS FACING INTERNATIONAL FINANCIAL ENGLISH INTERPRETING}

With the continuous development of economic globalization, financial institutions such as foreign banks and joint venture banks have emerged in China, and financial English has emerged. It aims to cultivate high-level compound talents with solid English communication skills, financial theory and related practical work ability, which has far-reaching significance for the stable development of China's finance services capabilities abroad [2].

There are also many problems to be aware of in hot issue interpreting:

(1) The professionalism of financial English. There will be a large number of hot financial professional vocabularies in the process of interpreting in the financial field. Many words have completely different meanings in the financial field. Relevant research pointed out that the source of financial English vocabulary mainly through the following three ways: first, borrowing vocabulary from everyday English; second, unique vocabulary in financial English; third, making full use of the hyphenation term [3]. The sentence patterns and passages of English in the financial field all have their own characteristics and need to be highly valued. 
(2) Accuracy and simplicity. In financial professional theories and institutions, many abbreviations are used, and a few short words are used to form an abbreviation. In many cases, it is not easy to confirm the words contained in the acronym, and there is a problem that it is easily confused with the company name and brand. This problem is more obvious in financial hot issues, and is often used in the internationalization of the RMB, such as the International Monetary Fund IMF, the Special Drawing Rights SDR, and the Free on board FOB. Accurate and concise finance in English is particularly prominent in international finance and trade negotiations between countries with international trade. The accuracy and simplicity of English is particularly prominent in international finance and trade negotiations between countries with international trade.

\section{ENGLISH INTERPRETING TEACHING STRATEGIES FOR INTERNATIONAL FINANCIAL PROBLEMS}

The process of interpretation is to understand and convey the meaning of the source language, combined with context and rich vocabulary, is a logical expression. Different people have different expressions, and different words have different extended meanings. Interpreting teaching requires training students to master important measurement index of interpreting skills. How to achieve this teaching purpose in the process of interpreting teaching, aiming at English interpreting of international financial problems, combined with the characteristics of financial English, propose the following teaching strategies:

(1) In the teaching of interpreting, students are trained to translate literally on certain financial issues. In this translation process, attention should be paid to the proper processing of long sentences. Literal translation is very practical for professional terms, professional terms, financial English literature materials, etc. It is an important translation method. Financial English requires professionalism and accuracy. Colleagues are also a highly applied subject. They are not only simple and clear, but also professional and special. For example, economic externality can be directly translated into economic externalities, herding effect is the herd effect, and foreign exchange market is the foreign exchange market. The translation of financial English passive sentences usually has the following three situations: First, the passive form of the original text is retained, and the sentences applicable to this translation method are translated by means of Chinese "being" and "for". Some speak the initiative of the action, some can't say the initiative of the action; the second is translated into no main sentence, the sentence applied to this translation method is often the sentence in the original text without the initiative; the third is to translate into active sentences. The sentences that apply to this method of translation are usually sentences with the initiative in the original text, or sentences in which the passive is inanimate and the active is not obvious. The purpose of this teaching strategy is to make the industry expression consistent with the financial English standard as appropriate, and improve the customer satisfaction in the financial field in the actual interpretation.

(2) In the teaching of interpreting, students are encouraged to accumulate a large number of basic professional vocabulary, pay attention to acronyms, and integrate financial knowledge content. There is an overall framework. International Finance English contains a lot of knowledge, such as international exchange, balance of payments, international currency, international investment.

(3) In the interpretation teaching, the differences between the Chinese and Western financial systems are compared.

China's financial system is a comprehensive financial system under the supervision of the central bank, with stateowned banks and state-controlled banks as the main components, and private commercial banks as an important component, implementing a floating exchange rate system. With the development of financial globalization, the process of China's financial liberalization has been accelerated. China's financial system has become more closely linked to the global financial system, and the linkage relationship has been further strengthened. However, due to the differences in the starting point, political and economic aspects between China and Western countries, there are also many differences in the accounting system from the West. For example, in terms of pricing theory, China is priced by cost, and the West is denominated by market economy. In terms of measurement, China commonly uses kilograms, tons and other units of measurement, the West commonly used metric tons, long tons, short tons, grams, ounces, etc., these differences have brought difficulties to financial English translation.

(4) Training students in interpreting teaching to master background and cultural differences under the premise of combining context

People's verbal communication is carried out in a specific social context. This social context mainly refers to the objective coexistence environment in which the speaker uses the language and the listener understands. The social context directly affects the understanding and expression of the dialogue between the two sides of the communication. If they have sufficient understanding of the social context and can properly use it, they can get better contextual effects and promote communication success.

As a specialized language for professional use, financial English has a specific use environment. Therefore, when translating, it is necessary to change the translation strategy according to the specific financial social context and master the professional translation skills. Financial English is mainly a function that explains it in the process of communication. In the process of financial English translation, if we can use the information provided by the context to carry out speculative reasoning and deal with the interpretation function of its social context, then we can fully and accurately obtain all the information contained in the original language. And it is able to analyze the meaning in its discourse and make a logical explanation for the discourse that is not logical. By designing relevant scenes and exercises in teaching, the goal is to train students to internalize knowledge into professional skills.

Specifically, the form of the financial interpreting workshop can be used to introduce the interpreting business scene of the real interpreter teacher into teaching. For example, in this semester interpreting teaching, I promptly 
introduced my latest simultaneous interpretation and interpreting tasks into the classroom. On Wednesday, September 6, 2017, the second overseas Chinese New Media Summit Forum Jingrong Town Branching Forum in Pidu Chengdu, the topic of this forum: the impact of artificial intelligence + on media development. The guests were from the editor of the People's Daily overseas edition, the head of Tencent's intelligent hardware, and the global accelerator Founder CEO Steve Hoffman. It uses a lot of knowledge in the financial field. We simulated the interpretation site and arranged for the division of labor, especially for financial interpreting training. The teaching training uses live audio, video, and speaking materials, which are highly realistic. At the same time, the parallel financial sub-forum of the event was introduced: the Belt and Road Initiative and Green Finance. The students responded well.

\section{CONCLUSION}

In the process of economic globalization, the importance of financial activities is increasingly reflected. With the continuous development of China's financial liberalization, there are cases in which the export translators are in short supply. In the process of financial English translation, only the correct and accurate translation strategy can be used to accurately convey the original intention of the original text, and it should be more flexible in the process of interpreting. In the face of financial interpreting, which has high flexibility and professional requirements, the requirements for translators are even higher. The most important thing in successful financial English translation is to correctly understand the original text and accurately express the original intention. Therefore, translators are required to standardize their own expression skills and improve their professional ability. In the teaching of interpreting, in order to keep pace with the times, financial English continues to innovate with the development of the economy. Therefore, interpreting teachers should pay attention to guiding students as an interpreter and should pay close attention to financial information. The basic requirement of interpreting is to accurately convey the content and use the translation strategy that suits oneself to express the original intention in a manner consistent with industry norms, so as to easily deal with the macroscopic and microscopic conditions. At present, the financial interpreting market still has a lot of demand, and in the face of competition, we need to explore how to optimize interpreting skills and strategies. Interpreters need to perfect themselves in the trend of the times. Interpreting teaching must keep up with these requirements and keep up with the development of colleges and social.

\section{REFERENCES}

[1] Zhou Zhaoguang. Analysis of the Trend of Economic Globalization and RMB Internationalization[A]. Proceedings of the 11th Annual Conference of China's Capital Research Society [C].2002.

[2] Su Lizhi. Discussion on Financial English Teaching Based on Current Events [J]. Ability and Wisdom, April 2013.

[3] Wang Shuhuai Zhang Xia. Characteristics and Translation of Financial English Vocabulary[J]. Chinese Science \& Technology Translators Journal, May 2004. Volume 17, Number 2. 